\title{
Transformation of Natural Value in to Spurious Value; Emerging Issue in Value Theory
}

\author{
Satheeshbabu Kollambalath
}

\begin{abstract}
In this paper an attempt is made to accommodate the quality of 'originality content' in our economic analysis and tries to find out whether any role is played by the disappearance of this originality and non transmutable element in the emergence of the economic instability in the free market economy. For this purpose, the value of goods or an asset, against the contemporary belief on value, is classified into natural value (original value) and unnatural value (artificialvalue). This classification is based on the assumption that contribution to value of product made by factors are dependents on rate / amount of 'net addition to real value 'in the visible and enjoyable form' and not estimated in terms of 'monetary value. Such values do not defame the original value accumulated by real addition of value. The unnatural value is artificial value accumulated on the product without corresponding additions of value in real terms. The purpose of this chapter is to describe the way by which this 'unnatural value' is generated and accumulated. In its original form, it is grown in financial market and then penetrates into nonfinancial market. In this chapter, an attempt is made to prove that unnatural value is temporary and transient with no foundation in the market and disappears soon after the growthof GDP.

In this apper $r$ a humble attempt is made to show that such growth in natural value can never exceed the unnatural value created by illusion and anticipation. But such disappearance cannot stop as long as financial market is growing on the basis of speculation, uncertainty and illusion on the value of asset. In this chapter it is aimed to prove that such artificial value is dependent on the extent of unnatural value element developed in the component of value in the financial market, which is rare to occur. This chapter also tries to elucidate that market instability which took place in the history of Europe, Germany, Italy and France, originated from the accumulation of 'unnatural value' over the 'natural value' and it is transferred from financial market to commodity market. Moreover, this chapter also tries to see the process of the evolution of the concept of natural value from the "physiocratic" period onwards. For this purpose, the value of gross product generated by a nation, in a given time, is classified into - (a) Natural Value and (b) Spurious Value. This classification is based on the assumption that the real addition of value to GDP are derives either from technological innovation or from the contribution given by labor or by both, and these become the dominant factors which bring in the growth of natural and elimination of spurious value. This chapter is aimed to show that the spurious value is dangerous and must be destroyed at its birth itself. The spurious value is related to the price and is generated from rise in the price without equable growth in the gross produce or growth in the value of product purchased. This value is also generated when the price at which commodity sold in the market covers price of spurious value, in addition to natural value. Such rise in the price does not correspond or do not have any relation with growth in natural value. The value, has been classified into 'market value' and 'natural value' to explain the process of accumulation of such artificial value on 'natural value'. This chapter also attempts to search out the inherent process evolved in the market, which leads to an inevitable divergence of these two values - market value and natural value - in the free market economy and disturb natural equilibrium of the economy. It is also a search for alternative strategies to bring these conflicting values together. In the transition stages of economy it is identified that the growth of unnatural market (share market, and stock market) in the free market economy can releases large volume of spurious value into the economy. This is more so in the financial market than commodity market. This chapter also recommends strategy to follow for preventing this unnatural value. It is also aimed to see that spurious value generated in financial market, following mounting speculation and uncertainty, can penetrate into Non-financial market, creating fluctuations.
\end{abstract}

\section{Meaning of Natural Values}

The term 'value of nature' must not be confused with 'natural value'. Value of nature (environmental value) means a state of environment having no side effect on Living and Non living organisms by pollution. The 'natural value' is quite different from that. It is not associated, in any way, with environment and side effect of pollution. The natural value is obtained from 'by birth' and not artificial in character which is inherited by an asset or goods and it is not associated anyway with Mother Nature, or environmental value. We need to understand, the meaning of these terms shortly before analyzing relation with value. The environmental or Evalue is the value acquired by environment from its non-polluted or pollution Free State. It is the value gathered by Mother Nature from its original equilibrium. The word 'Natural', as we see, signifies original and inartificial, with normal relaxed, unbleached, unadulterated and mutable quality with no restriction or regulation. In such 
quality, there will be the substances that is condensed and embodied in product which carries with definite path of movement with clear destination and reveal frankness in the thought. This isvalued as permanent, non depreciable and illegitimate quality that perpetually points to demerits of unnatural element containned.

All good things, which exist, are the fruits of originality'. (J.S Mill). A society made up of individuals who are well capable of original thought would probably be unendurable (H. L Mencken) as truth. However, the application of this originality content (Natural) in the economic theory of crisis is similar to the application of truth in our life as Gandhi did in his experiments of truth. Such enquiry is very vital to find the original source of deviation of economic equilibrium established by originality content at its origin and which was interpreted wrongly. Wicks and Fridrich von Wiser who had developed 'Natural value' concept, which was based on subjective estimation of value, were responsible for development of treacherous attitude to society and behaved sanctimoniously. Such deviation from originality in our economy is similar to disappearance of our truthful behavior which can produce adverse effect to some extent and which leads to economic crisis. This has to be analyzed before seeking the source of economic crisis. The relation between originality concept and market price cannot be neglected while analyzing the strength of Natural Value of the economy - opposite of fictitious value. Such natural substances in the Market are depend on the difference between the original price at which exchange should take place (natural value) in the market and the prices at which good are actually sold (market price) in the market, as per direction given by market force. If transaction is completed at price equal to original value, it is the indication of normal function of economy where there is no excess demand or short demand or excess supply or short supply. If Price is pushed up by excess demand factors, the prices of such commodity will neither be equal to value nor be original, but spurious.

The speculation and demand and supply force cannot push up the original value. We can impose artificial value on natural and unchangeable value and it is done by subjective imputation over which market has dominant role .Such imputation is based on subjective estimation and speculation which have no place in the value in real world. But certain thinkers - Marshal and Stanly Jevons and Wick sell - have misguided us by including illusion' in the value concept and thereby leads economics into a dismal science. What is original or non fictitious value? In real world, the original value as put forth by labour, as said by Karl Max, never reflect in market as long as speculation and illusion decides market value overriding original value. The value, which is determined by the strength of combination of original element contained in the goods or in the asset and, the value, which do not increase, merely by speculation of investors, illusion and uncertainty element of future course of action is the summary of' Natural Value'. The Natural value is the ori ginal value that cannot enhance artificially merely by the immaterial force of demand and supply working in free market economy or by speculation or hoarding. The value that grows with corresponding growth in GDP is natural value. Friedic von Wieser (1851-1926) of Austrian School of Economics is the noted thinker to draw the importance of Natural Value in the economic analysis of value for the first time and went a little ahead of contemporary economists in the estimation of value based on the social value, which, no other Marginal economist had thought of. We must salute him. Weser's value theory asserts that any value theory should be based on natural value (naturliche Wert) and value is natural phenomenon, and should be independent of economic system. His idea of natural value upholds that the value of property/asset in its natural form in market economy is a dream and is determined, outside the original value of the product or asset, by illusion and speculation which is dependent on the distribution of income between different classes.

The social value - which is dependent on natural value - can never be expected to rise, but diminishes and continues to diminish according to growth of uncertainty element in the economy which depends on the extent of equal distribution of income. His theory, in one sense, is a great contribution to economics in shedding light for future research. His natural value does not relate to original and hence it defeats the original character of substance. Such deviation, will lead to crisis in the capitalist system. The true value with its dignity cannot appear in free market system. The value of air which contains oxygen - that we breathe - cannot be estimated and would not reflect in the market and its value, will not fall below the original value irrespective of changes in market force and illusion and it is social/universal property The unnatural value is the value that can be enhanced by speculation, illusion, and uncertainty created by bidders or Bulls and grows and disappears like bubble with no real foundation in the economy. This artificial value grows spuriously without any growth in the GDP or without any addition to the existing content on product and it generates stimulus for bubble, which spontaneously penetrates from financial market to commodity market and leads to turbulence in economy. The unnatural value does grow in Financial Market and then penetrates into Commodity Market and create spurious value. To get sense of it, let us assume that the value contributed by shares of stock market towards GDP of Rs1crores is Rs.20,000/- Lakh and it is the contribution of share value alone to GDP. Assume that GDP has grown 5\% pa (5,000 crores), so that value of GDP is increased from 1 Lakh crores to 1, 05,000/- crores and it includes $5 \%$ growth in the share value in real term. The seeds of disequilibrium begin to grow and growth of share market and growth of commodity market are not corresp onding to each other and never tally and share market grows about 20-30 times high than commodity mark et. Suppose, the share value has increased from 20 
crores to 30 crores in this period and, the share value has grown from 20,000 crores to 30,000 crores during this period. It means that financial market has grown by $50 \%$ per year, while commodity market corresponding to GDP, has grown only by $5 \%$. The excess share value by, $45 \%$ over the GDP is 'spurious value', because there is no corresponding growth in the GDP according to growth in the value of share in the share market. In this example, it is found that the growth of financial market is much faster than commodity market, due to speculation, uncertainty, and illusion of investors, which do not leads to expansion of production. A high negative correlation has existed between stock and commodity prices over the past 140 years (Hanabuchi).The commodity market develops when stock market is in crisis. The reason is disinvestment of spurious fund from financial market to commodity market which encourages the growth of market of artificial value. The value to the public, as conceived in illusion, consists of spurious value but social value excludes artificial and spurious value.

The total value content minus uncertainty and speculation elements induced value is natural value. The unnatural value is the value accumulated by illusion, speculation, and spurious rise in value without any growth in the commodity market or without growth in the GDP. The growth of such value is equal to difference in the excess or short of demand over supply force created by illusion. The Commodity Market cannot expand merely by speculation and illusion. It is foolish to believe that the growth of Share Market can boost the economy. The speculation, illusion, and uncertainty do not helps to expand natural value of product and is an illusionary growth with no foundation in the commodity market.

A meaningful analysis of value should be based on the natural element, embodied in the product that comes under transaction. This natural or original element is not surreptitious. Yet they are at times being overlooked and hence absent in, many of the studies relating value, available from Physiocrates onwards. I am now more concerned with these marketing reflections of originality element contained in all goods in the determination of value product for society as a whole and in which they gave least significance to subjective value. Certain utilitarian economists such as W. S Jeovan (1835-1882) and Marshal did not treat value concept, for society as a whole, and gave importance to subjective valuation method. In this concept, we study the impact of environmental value and 'Natural Value' (original value) in determination of the value for society. "That value which arises from the social relation between amount of goods and utility, or value as it would exist in the communist state; we shall henceforth call "Natural Value."(Friedrich. VonWieser 1851-1926). By this social relation of value, he means total value, in economic sense, enjoyed by society and it is the result of combined effort of people, but utility obtained from this produce, is distributed according to ability to pay and it is limited and restricted among a few classes and there is no relation between net contribution to social product and total share of GDP taken by purchasers and failed to explain Social Benefit derived from the goods in his value concept which he loosely called natural. In this accumulation process of artificial value, this artificial value increases as economy moves from one state to another. By this concept, I try to define, artificial value and natural value separately from the total valuation of goods marketed. We can now see what does mean by this value and its influence in the determination of value, for society as a whole separately. To understand the natural value and its relation to price, we need to study about the market value. The market value is the value that determines the value according to strength of relative demand and supply force, under existing pattern of technology and prevailing quantity of money in circulation. The market value signifies the value depth determined by market force. It is not actual expression of original value, acquired from actual growth of products in the nation. Market value is not a permanent value, and is not consistent with actual growth achieved in the economy. It is transient and temporary and is subject to change according to change in the speculation and trading practice and uncertainty in the behavior of bulls.

If market value goes up above natural value and if price of assets goes on to rise without corresponding growth in the value of assets, the boom starts to blow off and economy falls into crisis. The concept of natural value is predominantly associated with prices of shares/stock, though it has significantly less asso ciation with commodity market. The market value of shares, as seen in share market, is determined more by demand and supply forces - forces outside labour content - than growth rate of profit of the respective firm. The demand consists of actual demand generated from the prevailing market force - the determinant of natural value - as well as demand generated from the expectation of future rise in value - the determinant of spurious value - are the two components of market value. With regard to share, the actual value of share is to be determined on the basis of dividend contributed to each share from the actual growth of business. The 'expectation'- generated demand for shares by 'Bulls' has least part in the natural value creation process. The bulls create speculative demand for shares, by bulk purchases and impose artificial value on the stock that raises the market value, much above the actual value. In other words, market participant creates speculative demand and drive the stock price above the original value. Any additional value re-imposed on the natural value by the drive of speculative demand is the spurious and unnatural value and it is created without any positive development in the profit of the company. 
The natural value of stock of shares is obtained by deducting any spurious or bubble value imposed by expectation-induced demand, from the original value derived from the actual. Marginal Economists especially Jevons (1835-1882) and Ben tham have already recognized the importance of subjectivefactor in the determination of value. This subjective imputation of value on commodities however cannot fulfill social objective of value and has independent existence and never consider unnecessary growth of spurious value. The unnecessary value or spurious value is illusion and has no direct link to real growth and is deceiving people about real growth. We cannot transfer this imputed value into the market where same price prevails for all people but with heterogonous subjective value, which is not the same for all consumers in a given time. Hence, we cannot measure social value for a commodity on the base of subjective valuation. Considering subjective valuation as a way of value measurement, labour do not have significant role in the determination of value in the market. Nevertheless, labour being the creator of all values, there is a question as to whether the labour or the psychic feeling (state of mind) may get the prominent position in determination of value. However, these two approaches towards value determination have blended together in the social value estimation concept and have eliminated the defects of marginal estimation of value and give respective position to both by accepting the 'averages of Rate of Use'( total number of rate of use - uses per thousand - divided by number of uses) in deciding social value. The same method is adopted by Karl Marx to solve the crisis arising out of differences in the ability and the productivity power of labour and introduced the term 'socially necessary labour'. Hence, the social value concept is introduced in order to explain the crisis situation aroused out of subjective value difference crept in at the time of the estimation of Natural Value for society as a whole. By social value, we are to think of nonmonetary value, instead of monetary value, which is subject to change according to change in demand and supply. However, Non-monetary measurement of value, if accepted, does not change according to change in demand and supply force.

\section{Evaluation of 'Natural Value'}

Aristotle (384-322BC) should be given first credit to classify the structure of economy into 'Natural Economy' and 'Artificial Economy'. He recognized the importance of Natural Character of Economy intrinsic character - in the economic crisis 20 Silent Victims Emerging issue of environment and found that this value began to diminish fast. He also realized that such inauspicious quality - extrinsic character penetrated in after the disappearance of barter system and subsequent formation of money dominant market. Unlike barter system, in the money dominant economy, goods are exchanged, not for consumption, but for accumulation of money. In this economy, there is inevitable and eventual arrival of extrinsic character which destroys natural character of economy. In the money dominant economy, to him, the dominance of Natural Economy over Artificial Economy disappears and this can destroy the foundation for the smooth working of free market economy. After the disappearance of intrinsic value in money dominant economy, the extrinsic value appears and it creeps into every corner of transaction like virus. The social rationality rather than individual rationality became criterion of intrinsic value, that is to say social value. However he failed to analyze the role of natural value in establishing 'social value'. (This will be explained later). The physiocratic thinker Lamercier Revire (1767), in his work "Natural order" has highlighted certain indestructible and irrevocable essence of nature that retains soul of humanity and deviates from the doctrine of dynamic nature of environment. To him, this dynamic nature of environment, which remains unchanged in all periods of time, is Natural Order. The change of environment is the essence of nature and man cannot change it. According to them natural value is moderate and the inherent thrive for maximization of happiness which is inhibited in every man and which cannot stop and which is acquired from self interest and treated it as sacred and eternal law of nature. This is the irrevocable character derived from inherent quality of natural order. Changes may confer infliction on our environment either by pollution, or by technological innovation. But such change, according to him, is inherent and irrevocable essence of natural order and it remains unchanged and cannot be deleted out by human action. This damaging effect of our actions on environment by pollution and its movement through the conductivity nature of air (moving character of air carrying pollutant content) helps to shift, and to carry the pollutant content generated in one nation to another and distributes adverse affect in all nations irrespective of nation that generate maximum pollution or generates least pollution. This character of air is the indestructible essence of nature which can never be damaged by pollution or human action. It is the natural value of air and not the environment value that is subject to change. The rude form of Natural value, is designed by physiocratic thinkers like DuPont(1737-1817,) Mercier de la Rivers, and Mirabue ,but all of them directly or indirectly associated it with their favorite concept of 'natural order' an d believed that every economic activities of man is controlled by Natural Order on which man has no control. For them, everything is below the 'Natural order' and it removes the artificial barriers in employing individual liberty to utilize the private property to the benefit of society. This 'metaphysical concept' of 'Natural order' is aimed to strengthen Almighty (expression of the will of God) power that is "governed by universe for bringing about universal happiness." Moreover, it aims to explain the inter-dependence between economic growth and natural order (the Will of God). 
The core of the system described by the Physiocrates is one of the powers of Nature - a system based on natural order (R.L. Reynolds). Adam Smith and J. S.Mill (1806-1873), obviously, are at ambiguity of the word 'natural value' and confused the readerswithout telling much about it and loosely associating it with instinctive power inherent in men for maximizing effort. At one side, Mill supports the private property for its immense power involved - the natural value (power that pull out inherent pot 22 ential) - stimulates for channelizing natural power inherent in men to full extent, for the benefit of society. On the other side, he is dubious about its potentiality in channelizing inherent power involved in all the people equally towards the growth of GDP. By doing so, he argued, private property comes into existence and that opens the door for the "robbery." He says that it ought to be abolished in order to bring in Liberty. He is the first economist to divert natural value from its association with nature or environment. 'Things obtained without labour or sacrifice has no value, however, useful it may be. However, he proceeds to add that things have greatest value in exchange, as diamond, for example, may have nil or no value if not in use. The word value and price used synonymously by early thinkers and are not discriminated even by Ricardo. Mill adds confusion and uncertainty over the concept of value theory. "Happily there is nothing in laws of value which remain for future and present writers have to clear up. The theory of subject is complete" (J S Mill). However, he has a vague picture about the value concept in relation to environment. The eminent physiocratic thinker Dr.Quency had attempted to equate social value in term of price and his work remained unquestionable until the advent of Recardian theory of rent. His pronounced and revolutionary theory in economics upholds the importance of 'nature' in determining value and price. This theory uprooted, Dr. Quency's concept 'what iscalled value is price'. Ricardo proved it drawing the character of diminishing fertility of land and assumed that value derived from nature is subject to declines to the extent of diminution in the fertility of Land. In addition, Market price of product from it tends to rise according to application of modern input devices such as chemical fertilizer and modern technology that compensates losses in the fertility of land. Hence, the price moves upwards to the extent of increase in cost of inputs. However, the value of product remains unchanged despite the hike in cost. How can we say that values and price are consistent in the context of diminishing fertility of Land? Following the diminishing productivity value of hand, the price and value of the product are divergent and inconsistent.

The market operations are often guided by the temporary advantage obtained from the economic abnormalities created out of "Bubbles". Hence the stock market price is clearly diverging from the fundamental natural value of asset. Nobel Laureate Dr Vernon Smith had drawn a chart in his work on "price of bubbles" showing net asset value in Spain in 1988-90 and found that, at the peak of bubble, the Spain traded near \$ 35; nearly triple its net asset value of about $\$ 12$ per share. However, this bubble burst out in a single year when many of the stocks are sold at high premium. The deviation from the natural value of asset either by high expectation or by speculation has lead to destructions of wealth and despair among people as seen in Mississippi bubble (1720). German economist Jhannan H. Von Thumen (1873-1850), also goes on distinguishing between Natural Value and Market Value to prove that natural value has never been consistent with market value (Evalue). Market value means artificial or value of nature towards which price always tends to move to reach an equilibrium. However, by degradation of E-value, price is always going up and up until it deviates from natural value, more and more towards artificial value.

The classical economist consist of J.B.Say, David Ricardo, Sismondi conveniently neglects the Natural Value generated from labour saving devices such as machinery and equipment. To them these devices transfer their value to the target of business, to which they are put to use and transfer their value equivalent of Val ue of depreciation during the process. The Labour saving devices transfer value equal to the value lost or depreciated. The question is how much values have been generated in the business from the installation of Labour-Saving devices. It is true that number of workers in pre-and post machinery installation period is the same but more value is generated. Nothing to wonder that it has been derived from Labour Saving devices, which transfer more value than it does lose. Some people think that the abundance of goods is enemy to value. For them the increase in the supply of goods brings diminution in value and found an inverse relationship between value and supply and demand. The creation of artificial scarcity to push up the value! For such people Great Depressionhit in Europe in 1930 is welcome state of economy as long asit pushes up the value of everything, creating scarcity. Margin a list - W. S Jevons, Marshal, and Bentham - estimated the value on the bases of scarcity and degree of wants to obtain such goods. Neither labour theory of value - quantity of average labour contained in goods - nor social value estimate on based on use value has equipped with sufficient tool to explain the role of 'Natural Value' in the determination of social value. Does social value of goods is determined by scarcity of goods? None can admit such a misleading philosophy that leads to wrong conclusion. In their interpretation, there appears a very vivid contradiction between determination of subjective value and social value. For some goods, social value is high and for same goods subjective valuation is low. For liquors, subjective valuation is high for those who use it and but, social value - that determines the existence of men - for same good is small. Thus use value determination based on subjective value is useless and leads value theory in to false estimation. 


\section{Spurious Value and Bubbles}

The meaning of Natural value would be clearer to the readers, if we go through the concept of spurious value. The unnatural value is that value which accumulates on goods or assets without having any growth in the real value of domestic products. This value, however, does not correspond to any growth in the portfolio of real wealth. This value has more relevance with the financial market that deals with the exchange of shares and stocks than commodity market. If the market value of the shares are rising by $70 \%$ in a given period, and productivity and net growth of the concerned company is growing only by $10 \%$, the excess value worth of $60 \%$ growth of share value over and above the real value is the growth of spurious value. The spurious value is unnatural value that inflates original value into 'illusionary over valuation' or 'illusionary under valuation' of asset market. This value acquires the strength and grows like Bugs sucking the blood from financial market where it is originated and penetrates into other Sub Markets of labour and commodity market. The original equilibrium obtained cannot remain stable for all time and it gets disturbed from the arrival of spurious value which is generated from the effect of 'illusionary valuation' in asset market. It is found that speculation, and illusion and uncertainty gets momentum in financial market and moves in to commodity market and burst like a bubble.

The spurious value grown in asset or financial market does not remain unmoved and gradually disturb all segments of market. Such value, once generated in asset market cannot be stopped and it ultimately will dislocate the equilibrium position of natural value. This accumulation of unnatural value, over the real wealth, is capable to dislocate the foundation of market economy, with inherent instability of price and promotes inflation and deflation alternatively. The under valuation of real asset value by owners of assets or wealth, below the natural value is nothing other than the situation of deflation. Such under valuation below the natural value, at existing market price, also expresses the situation of spurious and unreal value. Great depression of 1930's, which shook Europe especially Germany is an example of such situation.

If there is a situation of wide spread 'illusion' among investors that their wealth in the asset will go on rising, the market price of their asset do not fall. This will push up the confidence of investors. The increasing confidence with no corresponding growth in the gross national product is a serious concern to the 34 economy. This promotes dangerous growth of spurious value. In such situation, economy moves to upper limit of value wherein spurious value constitutes larger proportion of value. This spurious value will no longer become an obstacle for sustained growth, as long as the spurious value grown in financial market is confined to that market alone without moving to commodity market through increasing demand from spurious money generated from financial market.

\section{The Disinvestment of Spurious Fund and Bubbles}

In spurious economy, financial market can be more spurious and acquires more strength to earn more spurious value, but these value produce illusion of sufficient profit and stable growth, but the profit is temporary and within no time it disappear when disinvestment of such meaningless funds take place from financial market to commodity market. The profit grows and investment in share market expands as long as spurious funds move within financial market. But it is a dream. For us, there is no need to worry as long as there is no disinvestment of shares/stocks from Financial Market to Commodity Market. This does not occur as long as the growth of investment in the financial market is equal to the growth of spurious value generated. The burst occurs when fund reinvested in financial sector is less than the fund produced through spurious money. The equity between spurious value generated in financial market and spurious money invested in the same market is necessary for financial stability in the economy. The disequilibrium between growth in spurious value generated and spurious money invested will dislocate the economy. Let us assume that total value of GDP of a nation is 100000 crores, of which the contribution of shares is 20000 crores which include both spurious funds and worthy funds.

The natural growth fund (worthy fund) in the value of share market in portfolio of GDP, is estimated as $8 \%$ of it ( 1600 crores $=8 \%$ of 20,000 crores) and balance of Rs 18400 crores is spurious funds. This means that one-year investment of 20000 crores of shares in this market can help for an additional value of worthy GDP by 1600 crores only. However, this $20 \%$ of growth of share value is not real value as long as it is not followed by corresponding growth in the GDP, and fails to nullify the disequilibrium created by unnatural rise in the share value .Only $8 \%$ of GDP (Rs. 1600 crores) - the real growth (natural growth of GDP) - is added to GDP by growth of share value. The balance $12 \%$ of growth of share value in the market is the spurious value. By adding actual growth of natural value of asset in financial market, with those of gross domestic product in that period, we can derive actual growth in the economy $(80000$ crores $+16,00$ crores $=81600)$. The gross national product produced in that period is, thus, estimated as 81,600 crores.). Balance Rs 18400 is the portion of spurious value in the gross natural product. If these 1600 crores is withdrawn from the share market and reinvested in share market itself, there will be no disequilibrium in the economy and it would continue to grow. However, problem does not come as long as 1600 crores are reinvested in commodity market. However, issue emerges when the 
spurious money of rupees (18400) crores is disinvested from the financial market and channelized to commodity market. This is the prime cause for the housing bubble that shook major parts of USA in 2006. The issue can be explained in another way also. Assume that GDP of a nation is Rs 100000 crore, of which Rs 20000 crore is contribution of Share Market and balance of Rs 80000 crores is the contribution of Commodity Market (Rs $100000-20000=80000$ Crore). The whole of Rs 20000 in the portfolio of GDP does not represent real growth of output and major portion of it is unnatural growth of GDP i.e. share value is not followed by real growth in the economy. The natural value of GDP of Rs 20000 may be very much less than it and let us assume that only 8\% of Rs 20000 is the real growth corresponding to output ( $8 \%$ of Rs 20000 Crore $=1600$ Crores). The natural growth value of GDP is only Rs 81600 ( $80000+1600$ Crores) and balance of Rs 18400 Crores (100000-81600) is spurious fund having no relation with real growth of GDP. If this Rs 18400 is re-invested in financial market itself, there is no threat to commodity market. But problem arises when this fund is diverted from financial market and invested in commodity market. The gravity of instability in the economy is equal to difference between spurious growth of fund in financial market and volume of fund withdrawn from financial market and invested in commodity market. The economic instability, either inflation or deflation, is the result of the accumulation of the spurious value which is really generated initially from financial market. The Commodity Market has least role in the generation of spurious value. If we take either south sea bubble $(1771,1720)$ of England, Mississippi Scheme generated bubble in France and Great Depression in 1930's, all this instability was generated initially in financial market after the growth of spurious value and then gradually it moved to commodity market. Keynesian 'under employment equilibrium' which originated from deficiency of effective demand and his suggestion to resort to deficit finance, really aims to eliminate this deficiency of worthy funds. Great depression of 1930 in Germany originated in financial market of UK and US and ultimately gained momentum in Germany. This was the result of disinvestment of spurious funds from financial market to commodity market. The instability generated by financial market can dislocate value of asset and promote the formation of spurious value, and enhance market price spuriously, without additional value to the product. The rise in the price equaling the growth in the net addition of value to the product, does not, however, lead to formation of spurious value. For example motorcar with power break would be valued more than other wise. The hike in the price of car equals to net addition of value to the car, does not constitute price rise. In capitalist mode of production, as long as it continues, it is foolish to assume that market price and natural value will always be equal. However, they deviate upwards and downwards according to the volume of growth in spurious value. The spurious value is not related to market price alone but is also related to the purchasing power of middle class and elite class. If the purchasing power of middle class expands without corresponding growth in the gross domestic product, such growth is dangerous because this class alone enjoys the benefit in the growth of GDP. The temporary market gain without permanent growth in GDP is the root of economic instability and is termed as 'bubbles. 'The word itself expresses the meaning. Both boom and burst are the forms of bubbles and is inherent in free market economy. It is foolish to believe that bubbles are ultimately caused by the price variation (Hommes and Cars). Many observers quote that rise in market bubbles in UK, Australia, New Zeeland and Spain and some parts of USA in recent times, is not the result of price variation of assets, but the diminishing value of gross domestic product corresponding to growth of prices. The price is not the cause of value but dislocation of spurious fund is the case of value. The speculation and foolish gambling in asset market has acquired more strength after Neo Liberal Policy started in 1990.

The natural value, unlike the evalue, is not derives from the quality of Mother Nature. It is the inartificial and original quality, with irreversible and unbeaten character derived by birth and genetic quality of asset. During 1999 and early 2000 the US Federal Reserve raised the interest rate six times to counter balance 'bubbles' accum ulated on the market value of shares for stock. The "dot-com; bubbles" burst numerically on Friday March 10-2000 when technology heavy NASDA Q Composite index peaked 5048.62, which was more than double of its value just a year before. The market value and natural value of share deviated from each other in big way, an all time history. A great jump in the innovation and technology had brought significant changes in production along with quality of life just before starting of 'great Depression in 1930. The increasing demand for this innovative product had motivated many investors to make disinvestment of spurious money to invest it into new areas of investment that offers high returns than what was being received from the stock market. The sudden, disinvestment of spurious money, without corresponding space in the economy can, of course,effect share market adversely and produce reverse effect on the share value. This ultimately leads to Depression. The Economic Historian usually attributes this sort of, Great Depression, to sudden devastating collapse of US share market on October 29, 1929, known as 'Black Thursday'. The inflation of stock prices-begging stage of depression-has motivated stockholders to invest further under the speculation of better gain in the market. The Recession, started in 1930, had motivated investors to disinvest from the stock market to commodity market for further better 'gainful investment '. The Historic Examples of this type of crisis, that results in disinvestment and withdrawal of spurious money from share/stock market are' Mississippi bubble' in France Dutch 'Tulip mania Bubble'. In this entire crisis there is disinvestment of spurious money. The disequilibrium between 
quantity of spurious money invested and volume in the growth of GDP, can be found in all the bubbles occurred in various Nations on different period. 'The housing bubble' of USA, which recently burst out as Economic Bubble, effected many parts of USA including Alabama, Arizona, California, Florida, Georgia, Massachusset, Michigan. This is the crisis created out of falling natural value, below the market value following disinvestment of spurious money from financial market to commodity market. The Housing price reached its peak during 2006 and then it started declining during 2006-07. The house owners fell into crisis in August 08 due to Colalerized Debt Obligation (CDO) for the houses constructed using bank loans. The owners of houses mortgaged to banks for house loan began to sell out the houses at existing pri ce for fear that the prices may fall further. This resulted in the fall in market value of existing houses and banks virtually stopped long-term house loan. Besides, when repayment to the existing loans became irregular following fall in rent and land value, revenue recovery through sale of land became almost impossible considering the huge over dues in existing loans. Kaminsky and Reinhart (1996-1999) had conducted study on wide range of crisis in 20 countries including 5 industrial and new remerging ones. The common feature found then was that stock prices had risen about 40 percent per year above that which occurs in normal times. The bubble grew puzzlingly in Post Liberalization Period, after the growth of financial market. I am not against the financial market. However, this market needed to establish a strong link between Gross Domestic Product and market price of asset. Unfortunately there is no link between them. The illusion and feeling of reduced wealth in asset market is a source of growth of spurious value. When bubbles invariably burst, those who hold overvalued assets usually experience a feeling of reduced wealth and tent to cut spending which slows down economic growth.

\section{The Housing Bubbles and Spurious Fund}

The housing bubble is type of economic bubble that occurred periodically in local and global real estate especially in US real estate market due to the feeling of reduced wealth. The run-up in the price in both ownership and rental market had produced substantial growth in the supply side of house and number of houses started to rise substantially from mid- 90's through the late 90's. By 2002, the ratio of house to population rises, almost above $25 \%$ above the average rate over the three years immediately preceding the start of Bubble (199395). Everybody expected that Housing Bubbles in USA would collapse, along with the collapse of stock market in 2002. But instead of a collapse in stock Bubble, it helped to feed Housing Bubble. The loss of faith in the stock market caused millions of people to turn investment in housing as a safe alternative to stock market (Dean Backer 2002). The question is why investment in share market became unprofitable? The return from the shares/stocks remained unchanged during this period and was not profitable, in comparison with gains obtained from rent and fast rise in real estate (house) prices. The investors' illusion that their wealth in the stock market had increasedand they diverted part of profit (spurious fund) in stock market to house market, which, they thought, rose faster than the growth of value in share market. The investors, not knowing about the spuriousness of value of asset, diverted spurious fund of financial market to House Market to obtain better gain than share/asset market. The disinvestment of this spurious fund from share market, had taken place in almost all parts of USA in 2005-2008 period. During this period, the return from the rent of houses and price of houses rose higher than the return from the share market.

Motivated by this return above normal level, the investors in share market, where return was lower than real estate market, withdrew funds from share market and invested it in Real Estate market in anticipation of better monetary gain. According to US census Bureau, the House ownership rate had increased from 65.7 to $68.9 \%$ of the population during the period 1997 to 2005 . That is, around $3 \%$ increase in the number of house owners during the period. The withdrawal of money from the share market, and investment in house market, during this time, led to hike in the house market amazingly in the history of USA and it became attractive field of investment. The disequilibrium between the overall run up in house prices (stood at an average of $10.2 \%$ ) and growth of GDP by 2.8\% annually during 98-2006 was the result of diversion of spurious fund from share market to real estate market. This forms bubbles. The difference between Real Estate price and share market value, as shown in the above years is 8 percent, which resulted in formation of spurious value in the economy. The growth of house prices during this period compared to other asset in the market encouraged the investors to make disinvestment of assets. They redirected the spurious money to house purchasing which earned more revenue than any other investment. This disinvestment of spurious money from the financial market into commodity market led to birth of bubbles. The landed properties mortgaged with banks for availing house loan for ranging to period of 10 to 15 years. Banks were happy to advance. In this period of rising prices of houses, bank advanced maximum amount of loan on the mortgaged property. This spurious money was also directed for investment in house in anticipation of better game. The supply houses, did not witness a signal of a positive strength of US economy in this period. Such one sided growth, without having real growth in the gross national product has caused the release of financial crisis in 2006 known as housing bubbles. There would not have been any crisis or economic bubble in the house market, as long as money withdrawn from this market had strong link with productivity and GDP. Moreover this fund is not spurious and hence not dangerous as long as the 
funds moved within the share market itself. The situation changes when the spurious funds are withdrawn from stock market and deposited into commodity market where GDP growth is less than growth value of share. The bulk of investment which is withdrawn from the share market and diverted to Real Estate market, can lead to acceleration of price of land faster than GDP. The faster growth in the price of land can produce a sizable impact on the family budget portfolio. The growth in inflation drains away the income of middle class who obtained loan for the house and the repayment towards the house loan falls unexpectedly to the panic of bank. Consequently, a majority of banks withdrew fund for house loan. Many house owners sold their property and moved to remote areas to get exchange surplus. The extreme differences in the price of land in Metro and Rural areas have led to migration from urban to rural areas in search of better gain through 'exchange surpluses.' The value of land, throughout USA, in Urban and Metro areas had risen progressively along with disinvests of spurious fund. The land value rose by $85 \%$ of the total value of houses (Prof. Viseonism - 'Land Price in Six Metro Areas'). This bubbles started in Urban and Metropolitan area, and its effect spread to remote areas of USA when house owners were forced to flee from expensive locations of Metropolitan area, to the remote areas in the same region. The population of river side country California, especially in rural areas, had almost doubled (from 1170413 in 1990 to 2026803 in 2006). For example in 2005 during housing bubble in USA, about 1283000 new single family houses were sold due to the feeling that possession of house would reduce the value of asset further, forcing the owners to move to remote areas. The largest house Builders of USA such as Dr. Horton, Pulte, and Lennar had obtained the largest share in the revenue which increased considerably during 2004 and 2005. Dr. Horton's Stock rose from 3 million dollar in early 1991 to 42.2 million dollar in 2000-2005! The mainstream economists, including Chicago School, questioned the existence of "bubbles" in financial market and attributed the "real" factors for the emergence of crisis in financial market. The second view related to Keynesian line - the proponents of Behavioral financial school — which held that psychological factors including over expectation, under expectation, uncertainty, speculation, are the sources of "irrational exuberance." The reverse trend started in 2006-07. The first phase of bursting bubbles started when mortgagers of equity withdraws it for construction of new residential houses. The Bank Loans, at moderate interest, for construction of Houses in late 1990's and re-investment of fund (spurious) from the share market, had helped to have an oversupply of rental houses with vacancy rising near record Level above 9.0 percent in 2002 compared to a rate of 7.5 percent in Mid-1990. The fall in the rent and per capita income crippled the loanees resulting in default in repayment of the Loans. To prevent the collapse of mortgage industry and to boost up Home loans, the interest rate was slashed down- to a level of 50-year low-and it accelerated the run up in house prices. The real house prices rose by additional $31.6 \%$, from the fourth quarter of 2002 to fourth quarter of 2006 . This resulted in expansion of house constructions and peaked to 2070000 in 2005 more than $50 \%$ above the rate in pre-bubble years. (Dean Banker -2008) What happened in the share market during the period? As share value remained comparatively slow in growth, bulk of investment in share market was transferred again to House/ real estate market. United States subprime mortgage industry collapsed due to higher than expected house closure rate. More than 25 subprime lenders declared bankruptcy and filed cases. Thus, the disequilibrium between spurious fund invested and growth in the GDP corresponding to it is the main cause of economic instability. The housing bubbles enabled real Estate owners to earn more revenue. Dean Baker estimated that run up in the house prices created more than 5 million $\$$ in Real Estate wealth, compared to a 44 scenario wherein price followed normal trend in growth. The wealth effect of house prices is conventionally estimated as $5 \%$ on dollar which mean that annual consumption is approximately 250 billion ( $2 \%$ of GDP), which is higher than that it would be in the absence of housing bubble. The real per capita income had grown at respectable to $2 \%$ annually since 1997 but this is considerably slower than $2.8 \%$ annual growth from 1953 to 73 - a period with no run up in home prices. The proportion of House Loan Repayment Fund in the combination of Family Budget Portfolio rose fast, than any other component during 2003-2009. This acceleration was more due to diminishing per capita income and the inflexibility of house Loan EMI. This created disequilibrium in the family budget and the accumulation of spurious value in the economy. Of course, we do not yet recognize the role of share market in the generation of spurious value. The value of shares is vitiates from natural value (lower limit of price) to spurious value (upper limit of price ) according to volume of speculation and value changes artificially by speculation This is a cause of spurious value grown with inherent uncertainty Since, market value swings upwards and downwards according the changes in demand and supply force it, it cannot be treated as permanent, but as reversible in value. It appears as bubble and burst out in a short time. It is artificial and unnatural as well as reversible according to change in the demand and supply. Hence, such values are spurious and illusionary withimaginary foundation and have no existence of its own. We have to eliminate this artificial value creation process in the market, in order to keep away the market from sudden upset. The rise in the value of asset, in the open market, due to the operation of market force working in the free market economy, is the spurious and unnatural value. Many thinkers such as Merger, Wiksel, while analyzing concept of value, blended these components of value - market value and natural value into one value and did not succeed in isolating them. Marshal, Wicks, and Fredrick Von Wiser, and many other economists attempted to analyze the value, without 
separating the spurious value and hence failed to proceed. These inabilities from the part of economists misled the value theory into false conclusion. The growth of market value over the natural value is nothing other than birth of bubble. It is transient and temporary and burst out like a balloon. The economic crisis is generated from the growth of market value over the natural value. The bubbles are born out of conductive nature of price that travels in between lowest stages of value and highest stages of value that existed within the limit of price. These 'Limit' of price is the maximum or minimum level of value within which value deviates, according to change in the demand and supply force. The unnatural value or the spurious value, which was created out of operation of demand supply force working in free-market economy travels between these two limits of price. The rise in the price would not be a creator of spurious value in the free-market economy and cannot raise the price to a level, which will be harmful to economy. This is achieved when the price level, to the economy as a whole also, is equal to net addition of value. This is commendable situation and need to be golden mark period in the history of economics, if achieved. In such situation, the price rise would not lead to formation of spurious value. The natural value is not stagnant and stationary, at all stages of development and can rise to further higher level of value. The natural value for goods has added, at all stages of modernization and stimulation of the demand, by diversification of product through innovation in technology. This diversification of product and there by improvement of natural value to them, is a life and death for the businesspersons for his existence in the Market. The stationary state of innovation weakens its application to the product, and in turn it weakens the businessmen. The creation of additional of value to the existing product is not only the only way to enhance the natural value but it also is the way that must be created by increasing real purchasing power. The temporary solution confers attractive incentive for share/security holders to retain spurious fund with in the financial market itself. This accumulation of spurious fund, before starting in Commodity Market, took place initially in Financial Market and spread in the economy in general, forcing millionsof people to the very edge of starvation. It is obscene and insane that a few ten thousands of very rich persons (multi-millionaires and billionaires) artificially jack up, within months, by speculative gambling, a rise in the price of rice, wheat, corn, and other food staples, thereby forcing billions of people to the very edge of starvation. Obviously, such an abominable situation should not exist (James Harold; A brief Diagnosis of Depression). The spurious money generated from financial market, out of speculation and gambling is a dangerous source of wealth, which artificially creates an illusion that wealth of economy is increased. But, how it is possible to estimate wealth without adding to GDP? The spurious value expands and devalues all human efforts and therefore has to be curbed at any cost. Expanding rate of MRPL is the plausible solution for controlling growth of spurious value and this is done by reducing inequalities of income and by restricting disinvestment of spurious fund from financial market.

\section{Social Value Concept of GDP}

The social value concept and its relationship with GDP is a missing link in the determination of value and have to be discussed while analyzing natural value. This value concept is inseparably related to GDP and it cannot be separated from the rate of (per thousand of population) benefit enjoyed or Average Rate of Use of growth of GDP. Any study relating to social value excluding GDP will lead to false result and it is 47 foolishness as well as and non-judiciousness to do otherwise. In this method, the value is estimated on the basis of average number of people per thousand used a given commodities in a given time, instead of labour value based estimation. For commodity is concerned, such estimation, as did by Karl Marx, is not wrong but as far as social value is concerned, rather than labour value based calculation, the value estimation based on Minimum Requirements of Progressive Life (it will be explained later) will yield correct result and can render justice to nation. In free Market Economy, as long as the Marginal benefit enjoyed by additional growth of GDP goes to minority of people, the social value of GDP falls and it will, no doubt, shrink to the extent of shortage of benefit. It is foolish to think that the easy way to analyze the value of GDP and its beneficial effects on people is measurement of per capita income. This is rather unnecessary work and leads to wrong conclusion if GDP concentrates on fewer and fewer hands as it happens in free market economy which makes, wrong illusion that per capita income has grown and such wrong illusion develops especially after Liberalizations. Unlike contemporary thinkers like Amartya Senand Stigler, value of GDP or social value, , can never depends on both volume total productions and per capita income. It rather depends on justice in the distribution of GDP that can ensure minimum necessaries of progressive life for maximum number of people per thousand. The social value of GDP falls if only small number of people per thousand obtains minimum requirement of progressive life. In other words the social value falls in proportion to its accumulation of income on fewer and fewer hands that deprive necessaries from majority. Similarly social value will rise in proportion to reduction of accumulation of income and it is not depend on the than value content in the commodity. The Social Value of GDP is determined by Rate of Use GDP. The value of GDP discusses the effects of distribution of income on Average Rate of Use of them. This value is measured on the criteria of rate of enjoyment of this GDP by working class who produced it so as to get minimum necessaries of life. The issue is whether the growth of GDP is beneficial to people representing large segment s of population or only small segments of population. The Social value of economy 
is the study of natural value of GDP. Natural value of GDP is social value representing inherent capacity of goods for delivering benefit to the majority of people and reallocation of resources for equal distribution among people. However, this distribution of inherent quality of goods among various people dependents upon the justice in the distribution of GDP so that majority of people can make use of it. The per capita income and its growth in a given year (estimated by total personal income divided by population) is the concept used all over the world for measuring economic progress of a nation. We use this concept as indicator for measure ing standard of living, but faces difficulty in estimating progress of economy, especially in the context of running prices over a period of time than the rate of growth in personal income. This monetary concept is always related to prevailing price level, and an accurate estimation of real progress is not possible. In the context of spiral inflation grips all over the world since 1990, the growth in per capita income is not an indicator of standard of living. For solving this situation, the non-monetary concept of measurement of the standard of living including progressive requirement of day-to-day life is urgent need of the hour measurement. The method of assessing the well-being of a nation in terms of per capita income is totally false and needs substitution. The well-being cannot be estimated merely by growth of per capita income as is done now, as long as the per capita income does not count the percentage of population $\mathrm{n}$ which can obtain benefit of growth in per capita income to same extent of its growth. The MRPL concept is a non-monetary concept that can be used to measure the growth of the nation in terms of well being of people representing a large segment of population. This concept needs to be worked out. This should be based on the percentage of population which can obtain benefit or rate of use GDP for minimum necessaries of progressive life. We can now, measure social value ( natural value ) of GDP estimating number of people per thousand of population enjoying minimum requirements of life instead of taking average benefit obtained by given growth of GDP in a given time. This concept is to estimate how many people per thousand of population are able to enjoy the benefit of the growth in gross domestic product minimum necessaries of progressive life - and how many people, in additional growth of population, are enjoying the part of gross produce, which this generation contributes to it. The shortest way to estimate the natural value of GDP is to study the Ratio of Gross Produce to population, - rate of circulation of goods of minimum necessaries of life - which is measured in terms of use per thousand of population. This is the total value of goods and service produced and exchanged among the people-representing majority. The social value on this product is measured in terms of benefit GDP obtained by number of people per thousand of population. This social value of exchange depends on minimum requirements of life, which is subject to change according to growth of science and technology that brings more commodities in to market. The natural value of product means total value of goods required for 'minimum requirement of progressive life' exchanged in the country in a given time so as to enhance the availability of produce among 50 low income people representing the majority of population. The average volume of goods exchanged in the market per thou sand of population is termed as Product Population Ratio (PPR).

\section{Minimum Requirement of Progressive Life}

Minimum Requirement of Progressive Life (MRPL) is an important concept to be explained in the contest of social value of GDP. The term 'Minimum' never signify fixed quantity for all periods and varies according to growth innovation brought about by science and technology which bring in a variety of goods in the market and changes ways of living. The term 'progressive' is worth to mention. The necessaries are changes according to changes in the taste, and fashion etc. The requirements of progressive life are the unit of various articles and goods required for improved life to adjust with present progress of life. In the radically changing society, we cannot think of a life with out television, fan, radio and mobile phone even for ordinary persons are concerned. The items which were luxuries about ten years ago have become inevitable for progressive life and everybody and manage to get them by some or other means. The minimum requirement changes according to changes in age, fashion and culture. For instance, as far as income rises, the radius of their minimum requirement wills also be subject to increase. Cell phone, which was considered a luxury in the beginning, has become so much a necessity today that people cannot live without their cell phone! The minimum requirement of progressive life is defined in terms of minimum facilities including necessaries to afford minimum standard to keep up changing way of life, absorbing devices that have become part of life, in addition to food, clothing healthcare and shelter. For measure of minimum requirement, line must not be same in different countries at different period, and it depends on culture and technological level and level of income. Such a measure should look only to acquire minimum requirement of life and it is depend on the income distribution and the "social value of GDP." Note that if every ones real income increases, then the minimum requirement of progressive life changes. This, rather than depending on GDP, requirement obtained by each per thousand of population is depend on "product population ratio." The social value of GDP is dependent on number of people per thousand who can enjoy this M RPL, which in turn depend on Product Population Ratio. The social value of GDP is, I think, the most reliable scale for estimation progress of nation. Social value of the product or natural value of GDP is determined by the number of people per thousand of population who uses the product in a given time 
rather than the value content in the product. The social value of GDP is the concept that shows the relationship between net growth of GDP and net growth in rate of goods required for minimum progressive life in every thousand of population. While labour contribution or labour content can determine value of the product as Marx said, social value of GDP is not dependent on the labour value, but instead it is dependent on number of people per thousand who enjoy the benefit of such labour content. The social value of GDP is nothing other than its natural value. The quality of product is irreversible and original and cannot be reduced without consumption, as long as product's value is the result of human labour. In this sense, natural value of GDP is may increase, by enhancing product Population Ratio - the number of people per thousand who can consume it. On examining the value matter under such ground, the gold and diamond have less value than wheat and rice, which is, consumed large number of people per thousand. In India, wheat is consumed by the largest number of people estimated per thousand than any other commodity. On the reverse side, if minimum requirement for progressive life is obtained by less than any one or two percentage, as in the case of gold and diamond due to high prices, social value of GDP cannot be enhanced. The value of GD P can be measured by its social value of the gross natural produce. We use to give least importance to the subjective valuation in the determination of value. We count value for a society as a whole and call it as social value. For example India produces about $65-75$ million tons of wheat a year, which is about 35\% of India's total food product of $210-212$ million tons. About $60-65 \%$ of the people especially in UP, Punjab, Haryana, Madhya Pradesh, Rajasthan, consume this food grain as major part of the food of the people in these states. India consumes around 70-72 million tons of wheat a year. Most domestic consumption of wheat is in the form of chapattis, orrotti. In this analysis, 650 people per thousand people use wheat in these states. Hence, social value assigned to wheat is $65 \%$ of gross domestic value of wheat. The product with largest Product Population Ratio in India is wheat. It has high social value. Let us discuss about the 'social value of the products' in connection with Value of Gross Domestic of Product. The contemporary concept regarding the determination of value is based on quantum of labor power spent on production. To add more strength to this concept, we intend to incorporate VGDP concept in the determination of value of the product for society, as a whole. It is dependent on rate of use (Per thousand of population). The social value of the product neither depends on demand and supply force, nor on labor content required to produce, as believed by classical thinkers. We have no doubt, and belived that until now, that value of any product, is determined by quantity of labor embodied in it. Considering this explanation, this labor value concept occupies significant position in respect of subjective valuation but social value of GDP determines whether the labour content in the products benefits the majority of people. In the aforesaid example, the diamond has high ervalue, though it has low social value than wheat. If it is possible to extent this subjective value concept to social value, then the diam ond has no social value, as it is not part of our day-today life. Similarly, GDP does not have social value unless majority of people obtains the benefit. The value of GDP of a nation is strongly related to the rate of use of factors enriching quality of life such as, life expectation, literacy, education, child welfare etc. The Human Development Index (HDI) introduced in 1990 by Paki stani Economist Mahubul Ul Huq and Indian Economist AmartyaSen was not discussing the social value of GDP as a factor of distribution of GDP and its rate of use. To them Norway stands top in HDI ranking with life index of 0.938 and USA 0.902 with the sixth position. The GDP, as we know, is the sum of goods and services, marketed for sale, excluding imported goods and its value is not dependent on the quantity of goods exchanged in the market or total goods produced. It is not the quantity of goods and service produced in the country that determines the social value for GDP. Though the quantity plays a significant role in the social value product, the rate of use of product among various segment of people, has occupied a dominant part in the determination of gross natural product's social value. The volume of GDP and its Rate of Use simultaneously determine the Social value of GDP. If GDP rises and Rate of Use falls, the social value of GDP never rises and vice versa. On other side, if GDP rises by $10 \%$ while Rate of Use determined by MRPL rises by only $5 \%$, then Social value falls by $5 \%$. But remember that, if GDP falls by $10 \%$ and Rate of Use rises by $15 \%$, then such growth of social value, which is not proportional, does not lead to growth in social value and it rather results in less proportional growth in social value than actual growth in the rate of use. In order to achieve higher social value of GDP, the Rate of use should grow more than growth rate of GDP. The growth in the technology has vital role in the expansion of production. But it is foolish to conceive that advance of technological innovation in the products determines the value. The Government of democratic set up has the responsibility to distribute gross domestic product between people equally and create demand for goods from all those who is in need. It is the indicator that decides social value. The technological innovation in the production helps, in many ways to enhance the volume of GDP and it helps to shift the level of GDP from lower to higher level. Nevertheless, the domestic natural value can, shift backwards to lower level when the benefit of innovation is grabbed by the well-to-do and when minimum requirement of progressive life cannot be raised according to growth in the innovation. This Minimum Requirement of Progressive Life (MRPL) is not a permanent boundary to which any change effects. It is subject to shift forward above the boundary of this minimum requirement in accordance with the advance in production and outlook about life. The shift in the Natural Value of produce from one level to another level may indicate 
not only increase in the volume of GDP but also the reduction in the gap in Product Population Ratio. The experience in developed nation like USA, France, Mexico, etc. shows that gross natural value of products is down wards due to reduction in the product population ratio. The level of Natural value of produce is also not permanent and is subject to change according to change in MRPL inclusive of new product as a part of day-today life and upper limit and lower limit of price. The shifting of Natural value of product from one stage to another stage, subsequent upon growth in the net addition to value of product and growth in the MRPL can be explained with the help of two concepts - upper limit of price and Lower limit of price.

\section{Limit of Price and MRPL}

The rates of use of MRPL are not determined by the movement of price Level (General Price) between these Limits. Such prices are not motivated by the price hike initiated from all the commodities marketed. Instead, the price hike of one or two commodities of multiple linkage effect determines rate of use of MRPL and it subsequently, without much delay, it affect the prices of a large number of commodities, and brings in enhancement of price of all the commodities marketed. The price hike generated from one or two commodities penetrates into another market, without adding additional purchasing power, among vast majority, and without modifying the quality of product with innovative strategy of people has been playing a great role in reducing rate of use of MRPL.

The disparity between the growth in price and growth in purchasing power among people representing majority widens the gap between upper limit and lower limit of price (we will explain below.) The price hike by such strategy is beneficial to Government, in collection of collection of Taxes as long as 'the price hiked product' is inelastic. These kinds of unwise strategy are employed to meet temporary requirement of fund, despite they well aware the in long run the net effect of such rise is spurious and nullify the result. As a result the profit generated out of such rise continues for long time than what is seen in the economy in general. These highly sensitive commodities are mainly petroleum products. The demand for these products does not respond according to changes in price hike, and de and, goes on even at the higher price and government can mobilize the fund, in full extent of expectation, without any fall in fall in demand. Hence, price hike taking place, in general price, is generated from the high sensitive commodities and penetrate into commodity market. Both upper limit and lower limit of price play important role in the determination of the social value of the product available for sale. The rise in the price without corresponding additions to the product would, of course, reduce social value of product. Similarly, additions of value to the product without equaling rise in the rate of MRPL will also reduce social value of pro duct. The upper and lower limit of price, really, implies social 60 Silent Victims Emerging issue of environment value of product. The limit of price reaches its upper limit, expanding gap between two limits, if there is perpetual rise in price without growth of GDP and these results in accumulation of artificial value over original and natural value. The reduction in social value of product is, always, equal to rate increasing gap between natural value and spurious value gathered in a given time. This limit of price discusses the limit, between which social value of GDP changes according to growth rate of MRPL. This social value of GDP cannot remain static and shows diminishing trend and price tend to rise as long as growth rate of MRPL begins to fall. Inversely, the social value of GDP shows an increasing trend and price to fall, but not to below natural value, as long as MRPL rise. One thing to remember here is that, these value determination processes should never consider subjective assessment of value for their reflection in market price and assesses only social value measured in terms of rate of use. Both limit of price is not acceptable for us, as a most desirable choice. The price should settle somewhere else between these limit at which there is neither spurious value nor under-value of goods.

We should remember that upper limit of price is not a permanent level at all periods and today's upper limit may become the lower limit of price tomorrow. This shifting of limit of price is dependent on growth in additional value of the product and growth of Minimum Requirement of Progressive life. If the price rises without growth in per capita income, measured at per thousand of population, the upper limit of price goes up ward, reducing this minimum requirement. If price rise is less than growth in gross domestic product, the lower limit of price goes upwards and the gap between upper limit and lower limit falls accordingly. The mere growth of GDP, without rising rate of MRPL can never bring down price from upper limit as long as its growth do not reduce the inequalities of income. 61 There will be no place for spurious value, when MRPL rises along with the growth of GDP. The growth of MRPL, corresponding to or more than growth of GDP, can bring/push up lower limit of price upwards and reduce the gap between both limit of price - upper limit and lower Limit. Our main task is toreduce growth of spurious value at its source. As long as spurious value generates shift of capital from Financial Market to Commodity Market, we have to curb this venture at any cost. For this, I feel that certain limit should be placed for fall or rise in the value of share so that there should not be any bulk withdrawal of spurious fund from financial market. There should be a percentage to spurious funds that could be withdrawn from financial market in a given period of time andit must fixed by the statutory body concerned. This minimum should be fixed in accordance with the growth rate of MRPL and GDP. If growth rate of MRPL is excess in 
comparison with the GDP, more spurious funds from financial market can be withdrawn without adversely affecting the social value of product. On the other hand, if more spurious funds are withdrawn and invested in commodity market without growth in the rate of MRPL, purchasing power falls and will lead to fall in GDP. The demand for goods finds a space to grow and yield return to investors only if the Rate of MRPL grows in accordance with the growth of GDP. The social Value of GDP is dependent on Rate of growth of MRPL in a given time and the value can be controlled through re- distribution of GDP to achieve high rate of MRPL. The increasing inequalities of income are prime source of growth in spurious value and need to be reduced for subsequent elimination of it. Since 1980, many lower income and middle class consumers in the United States of America have reacted to stagnation of their real income by reducing saving and increasing Debt. This temporary fall in private consumption leads to reduction of aggregate demand and employment, and thus also contributed to creation of bubble which eventually burst ( Reghuram Rajan- Fault Lines 2010 ) This is nothing other than fall in the social value of product followed by fall in the rate of MRPL .Just like GDP has social value and its value is shaped by rate of MRPL, the money has also social value which is also determined by MRPL To obtain high social value for money, this rate should be sufficient to maintain minimum requirement for progressive life, in a given growth of GDP. The value i.e. social value of money is dependent on availability of MRPL out of given money

\section{Natural (Social Value) Functions of Money}

The traditional definition of Money is limited by several factors. This definition incorporates only life less and 'non catalyst function of money' such as store value, medium of exchange, and standard deferred payment function and neglects its 'social and catalyst function'. This conventional function is deadly and inactive and stationary in its function. It never include lively role of money derived from the distributions of money and its effects on the determination of 'Social Value of Money'.. The traditional function are one sided and explain only stationary and unproductive side of money and never tries to be associated with velocity function of money. This function tells about the relationship between rate at which money transfers from one hand to another and rate at which this movement of money discharge asset to every hand through which it pass. The money is not money which do not create asset in every circulation. The conventional definition does not tell about the role of money in the formation of social value of commodities under exchange. This 'Circulation Function or velocity function of money cannot be ignored in the definition of money as long as it is the function that make money to circulate. This characteristics give us obvious the relationship 68 Silent Victims Emerging issue of environment between circulation of money and productive role of money. This is the function that determines the capacity of money to perform exchange functions in a given time. Both are interdependent and it cannot be ignored. Since, velocity of money has been playing an important role in the enhancement of social value of both commodity and money, the definition of money should start from inherent velocity characters of money. The velocity of money being related to asset creation, the less velocity, is always associated with the less productive function. The velocity of money is the product of the inequalities of income, in all free market economy. The more inequalities of income, the less will be velocity of money. Hence the reduction of velocity function affects adversely asset creation power of money. This definition treats both money and commodity has exclusively independent function and fails to associate the role of money in the determination of social value of commodity as well as social value of money The traditional definition treats that both-social value of commodity and social value of money - are belonged to separate wing and neglects the interrelationship between them .They also reject the role of circulation and medium of exchange function in the determination of 'Social Value of money' and accepted quantity theory in the estimation of money value. The social value theory is nothing other than the natural value of money that shows interrelationship between social value of money and social value of commodities. Both are expressed, in the valid sense and bear meaning only under the circumstances where majority of people in every thousand are able to obtain Minimum Requirement of Progressive Life. These functions are natural and tend to be truthful in its duty if natural function entrusted by society to it is done perfectly. This function is meaning full only when all money under circulation are capable to perform all function of money to all people that can rise rate of use of MRPL equally. The natural function of money is really its social value function and it never ignore, distribution aspect of Money in the determination Rate of use of MRPL.. These functions stress the importance of distribution of money in the realization of objective - maximum welfare to all - for which money is printed . The more rate of use of MRPL, the more will be realization of such constitutional and social objective and less will be captivity of men to earn income for which constitution targeted.. Such distribution aspects are to be considered as eminent for society which considers social value as prominent over private value. Since, the inequalities of income and wealth are related to distributional aspect, and as such inequalities are invariably subject to rise in free market, the velocity circulation of money cannot be expected rise. This shrinking velocity of money is the facts thatstill threaten the market economy and, it contribute a lot to reduce the function of such money to that extent. The less the inequalities of income, the more will be the natural strength of money and vice versa. The circulation of money 
is limited by such inequalities and reduces asset creation power of money.. The naturality function of money disappears as and when money fails to render all its function to all people for whom it is minted. The disappearance of in the natural functions of money is equal to reduction in the rate of use of MRPL The more rate of circulation of money in a given time, the more will be the asset creation and medium of exchange function. Hence we can say doubtlessly that money can, perform its Social Value Function if there is the increased rate of circulation. Unfortunately 'the relation of production' in capitalism as Marx told, help very few to accumulate money in the form of asset or wealth leading to reduction in the rate of use of MRPL. Hence the rate of distribution of money is the determinant of the Natural (Social) Value function of money - the cornerstone of value of money. I prefer to give importance to, the distribution of goods in the determination of value of goods as well as value of money and give least importance in the volume of labour in the determination of value of goods. The value of goods is dependent of rate of use of that good and it fall as' rate of use fall and rise if rate of use rise. The rate of use of MRPL goods that can be made possible at existing price is the determinant of value of money. Some economist neglects this distribution function of money generated by its circulation function in the value. For them, value of money - either precious metals- and precious stones - is dependent on value of goods that can be purchased out of it and failed to consider rate of use of MRPL in the determination of value of money. They called any instrument as money if it is capable to perform functions of settlement of debt created by transaction of goods and services and they impute value to goods for society regardless of member of people use it .For them goods having rate of use of - say - one person in a crore of population has been given same value, to society as to that of goods having rate of use 95 lakhs in one core of population. In the same manner money has also social value as long as it is circulating with social objective. This is more important since money acquires value from the justice in the distribution of money. The more distributional justice of money, the more will be social value of money and vice versa. This is particularly so as long as value of money, as we presumed, is dependent on the ability to obtain MRPL for maximum number of people estimated at per thousand of population. In such estimation, the value of money rise in proportion to growth in rate of people received MRPL and falls in proportion to moving away from MRPL. In our concept, the statues of MRPL will never be downward flexible and always show upward trend. Such a trend can be seen and became a part of our society so as long as innovation in the production are absorbed by products in the form of arrival of new product in the market and became an integral part of life and became part of MRPL The money is not worth to be called by the name as long as it is fail to be distribute for obtaining maximum MRPL. The definition so far received, never considers justice in the constitutional function relating to distribution of money .To traditional concept, money can performs its function despite it is served for limited people. It is strange to think how money can perform its function while people for whom money is printed are denied from its function and goes out of MRPL. Such definition neglects circulation function of money and subsequent generation of Social Value function of money. For them money may be any good - such as gold, silver, copper, rice, salt, peppercorns, large stones, decorated belts, shells, alcohol, cigarettes, cannabis, candy, etc - that is widely used and accepted in transact ions to settle debt involving the transfer of goods and services from one person to another (John N Smith) .Money cannot perform its duty when it is locked up and ceased the velocity of circulation .According to this definition money can perform its function even when it is locked up and even when there is no commodities in the market and it has value in the absence of commodities. All medium exchange such as notes and coins or any other means are representing substitutions of goods exchanged. Money is not only the material representation of market transaction of gross produce of nation, but also it cannot be separated from market as long as there were goods ready to exchange in the market. For them, money has independent in existence and bears value even without goods in the market. Such definition is truly unscientific. Money either paper or coins that do not supported by proportional gold reserve, does have no value in the domestic market. Such money do not have value without goods are corresponds to them. The Commodity Money such as gold coin or silver coin can derives from value its intrinsic value and acquires value even without goods in the international market as it internationally accepted exchange medium and have no value in domestic market. This 72 Silent Victims Emerging issue of environment proves that exchange function of paper money is derived from commodity for which exchange is conducted .There is no need for money as long as there are no goods and value of money rise as commodities relative to money expands and falls as MRPL rate, generated out of such commodities falls. The meaning of money is derives from goods marketed for sale. In all definition, the representation of commodities ready for exchange is ignored. Any definition excluding the relation between medium of exchange and goods ready for exchange is false and meaningless . The definition such as "money is what money does " includes the function of money such as - medium of exchange, store value functions, and standard deferred payment - cannot be accepted as full fledged definition and fails to incorporate multi linked role in canalizing productive potentials with purpose for which it is minted. Conventional definition lacks the function generated 'from Velocity of Circulation Function - and subsequent generation of social value function of money formed by MRPL. Such inactive and insufficient definition leads to false conclusion that any devices of exchange that do not circulate and that do not add productive efficiency 
and that do not add social value is termed as money.. This function of money is needed to incorporate in the definition of money. Mere exchange of this medium for commodities without releasing stimulation of production of same is not money. Money should have life and blood, through which employment, production should expand and any definition of money excluding natural function is meaningless. The definition such as "anything that is generally acceptable as a means of exchange and at the same time acts as a measure and store of value is called money" (Crowther) and, "money is anything that is commonly used and generally accepted as a medium of exchange or as a standard of value" (R.P. Kent) has lacks the natural productive functions of money and need to go more further. But unfortunately, all such definition restricted the inclusion of missing link between human labor and environ mental resourcefulness. Such definition is remarkably sparse and centrifugal and leads to wrong conclusion that money is means of accumulation of income and wealth. Money is meaningless as long as it does not possess minimum velocity and potential power to generate incentive to engage business activity. Such definition of money neglects socially alarming situation of diminishing exchange and store value function due to price rise .It is theoretical strait jacket and social injustice. The store value and exchange function of money do isolate the value concept from them and makes basics indifference with social value function and exclude the fundamental and revolutionary power of money in canalizing man power. Money, as by its natural in its functions, has entrusted with social order for re distribution social values and gross produce. Any unit of money should be live in circulation at all the time and generate and accelerate velocity of circulation through transaction .A unit is worthy to be called as "money" if it has sufficient circulation velocity and are capable to generate incentive to business activity that add to Gross produce .A men keeps money in safe locker for a year, without being allows to perform its functions can never be called as Money. As long as money is locked up, it is mere a piece of paper without value. Keep money in idle means restrict them from its entrusted work, It gives discourage for undertaking business. The money can performs its function effectively only when it is possible to use it as a standard deferred payment as a benchmark for specifying future payments for current purchases that is, buying now and paying later for an amount as is determined during agreement of transaction time. This does mean that future payment of, any debt should involves compensation for loss of value because of the rise in price. Such loss of function, against what is expected from money are, really, not worthy to be called as function of money but rather unfulfilled or unrealized function. How can we measure store value function andextent of success maintained in keeping stability of value if loss of value is not compensated? Subsequent on rise in price, this function may seem to obscure and withhold the function equal to loss of the store of value. How can value, of money be measured if the store value function diminishes? The diminish in the value is equal to loss of goods that can be purchased at the time before price rise

The definition of money has been needed to give life and, energy in the transaction process and, must be incorporated this element, and identity such function as superior of medium of exchange function. In post barter period, there is no goods without money and there is no money without goods and however, money is related and interrelated with goods in both ends and goods is life and death matter for money .The goods is everything and release into economy as long as labour and labour power is there and money has only the role of servant. How foolish to discuss the servant neglecting the master. The goods have value without money and inversely money has no value without goods. The definition of money and its function without incorporating character of goods is seemed to be incomplete. The definition of money without telling the goods is partial and hence unacceptable The money circulates between financial institutions without corresponding exchange of goods has mere paper value only and hence spurious 'The money has function of distribution of GDP among various class who produced it. It is its natural functions. The share of GDP enjoyed of each do not have any association with share of his contribution to it but unfortunately market mechanism determines it and is depend on volume of money possessed and circulates in the economy. In this scene, cheque is not money, as called by contemporary thinkers, unless supported by sufficient fund in circulation and the money that is not in circulation has not worthy to call by that name. In this sense, unless accepted by people, the fiat money or note of debit without intrinsic use value - is not money as long as it lacks productive velocity functions The bank deposit, without circulations is not money. The volume of money possessed determines volume of goods and service that can be grabbed from the GDP by each individual. The exchange function of money, as defined in the definition of money is irrelevant when something of valuable content handed over for settling the debt created by purchase of another equal valuable content. The money being paper or coin of metal, cannot be valuable content and hence not worth to be called as exchange. The coins or paper money are not entitled to be called valuable content because it do not satisfy the condition of value such as irreversible quality, permanent accountability

\section{Value for Money}

The values for money (VFM) are now used synonymously with 'value of money' without conceiving the difference between them and need to analyze separately. This important to understand the function of money, as a medium of exchange and its source of emergence of Social value of money. The VFM is relates to 
effective and economical and efficient utilization of money available, within the budget constraint, in rational behavior, for achieving best result. For assessing of value for money it requires overall result of cost and benefit of investment and weighing and comparing overall cost incurred, without waste .The value for money for Purchasing a Television set is relates to maximum best technology employed in the set, in that time in least minimum price that buyer calculates. A utility derived from every purchase or every sum of money spent Value for money is based on not only minimum purchase price but also efficiency and effectiveness of purchase 76 Silent Victims Emerging issue of environment Many precious items having value to public such as naturally scarce precious metals, gold silver etc have been used as 'commodity money' whose value is equal to value of metal used. The value of commodity money is derives from the Commodity out of which it is made. The commodity itself constitutes the money, and the money is the commodity. The commodities - such as gold and silver - that have been used as mediums of exchange became scarce in supply among non-colonized

countries that were not inherited by gold mine or and were sufficient in England because they collected from its colonized nation like India These items were sometimes used in a metric of perceived value in conjunction to one another, in various commodity valuation or Price System economies Some pointed out that the inflation and deflation is the result of unrestricted expansion of such money( paper money having no intrinsic value) for which there is precious metal is required to produce. Money must have given frequency of circulation to have market value. Any unit of money should have value in between one (lower limit) and infinite (upper limit) and can never be zero. A unit of money - whether big or small - must have value, at least by small unit and this value is to run in between one (lower limit) and infinite (upper limit) at any level of price rise in a given period .This value centrifuge from given centre and revolve around it like earth rotate sun and any of body revolving around it will never goes to sun Such, revolution of value around the lower limit, but never moves in to it, determine the value. The paper money or fiat money do not have instinct value of its own and acquires value from the goods. But goods acquire value from the labour or from average socially necessary labour, as Marx said. Hence the value of money should be equal to value of Goods Marketed. Marx theory of Money is based on the Labour theory of value.

Commodities are exchanged each other against money in proportion to socially necessary labour requi red to produce it The variation of value of money subsequent on the rise in price do not express fall in the socially necessary labour and it may remain unchanged, but value falls There has been ambiguity in meaning; generally accepted thought of this riddle concept is that it does relate to something good that anticipated being perpetual in nature. However the re definition of this term should be, touched of human face, and which has prime importance especially in the contest of explaining value of money. Hence I devote peculiar attention to define value especially in the contest of explaining the store value and exchange function of money. To some Money is legal tender instrument - generally consisting of currency and coin. - used as medium of exchange to settle debt and for performing store value function to be used in future. Money is often synonymous with cash, including negotiable instruments such as checks. Can money the store it value in its stabile manner and renders same goods and service in future period out of given volume of money? To yield the benefit of store value function, money must possess power to protect its value in exchange as it is and exchange should be shield by stability character. As long as money, except in Gold standard, fails to keep the value and holder of given money in cash has to face the issue of evaporation of its value like water evaporates in heat A man ' $\mathrm{A}$ ' who hold cash in hand for Rs 1000 in 1998, by which he can purchase $100 \mathrm{~kg}$ rice then, do not mean that he can purchase same quantity of rice in $2010 \mathrm{He}$ may can obtain $50 \mathrm{~kg}$ only. This means that $50 \%$ of value of money evaporates without conferring any benefit and reduce medium of exchange function equal to loss of value. The store value function is Master function of money since all other function such as medium of exchange, standard deferred payment function are generated from it The money may be paper or a coin or any other instrument with physical entity and commonly acceptable and it is authored by central government to settle debt created out of grabbing portion of GDP for personal use .Money can be a social instrument designed by government to establish claim over goods and to establish private control of goods produced by society as a whole. Marx defines money, the general equivalent of value, as a commodity. According to Marx, the exchange value of a commodity is merely the proportion in which use values of one sort are exchanged for those of another sort (Marx 1867a: 13, 23.Marxian concept of money is related to expression of value of commodities. A significant number of contemporary Marxist authors defend the point of view that Marx's theory is compatible with noncommodity forms of money (Lipietz 1983; Foley 1986; Reuten 1988). The money cannot be commodity and its value is not equaling of labour value contained. Since its value depends on external factors such as illusion and anticipation, its value is artificial and temporary and disappears to the extent subjective valuation. The value of commodity to society never changes similar to money whose value changes according to illusion, uncertainty and expectation. The money is treated as inconsistent with commodities and two were treated separately in isolation of sociological character. The social character of money, is found to be erected out of illusion which spurious in comparison with the goods whose value is camouflaged by useless paper. Does all money lying in bank or cheque without sufficient fund in bank can be treated as Money? 
It is foolish to treat that money unsupported by sufficient goods as money. The money unsupported by Goods is spurious money. Such definition should covers all spheres of life including socio and economic life of human that should points to worthwhile situation, with definite destination, and that should accept for public merit. The concept 'value' must be defined in its real sense of social responsibility, for which we should neither be selfish nor be inhuman and it should contain humane face. Such social approach is inevitable for an economist is concerned as long as he is committed to society and it must be $79 \mathrm{~K}$. Satheesh Babu bases of all value theory whether social value or economic value etc. The Value, in whatever meaning, cannot be an unworthy quality of our life and it is a principle or standard quality considered worthwhile or desirable state of situation which is required for avoiding ridiculous state of affairs of our life. The social approach, in the definition of value and value of money - which need not to tell - is need of time. History cannot for give us and pushed out in to waste box if ignore the value of money decided by majority and if subjective valuation method is accepted for determination of money value. The value acquires strength when it began to diminish and it is permanent quality lying in between zero and negative and it will not come into discussion while it is rising. The positive value is the requirement for which we are fighting. Value is necessary requirements for bringing hedonistic and justice full way of life. This is a worthy full and legitimate vow that is longed to be permanent state. But often these values deviate downward and became more and more eroding affairs from way of our life. In economics the value bears wider meaning and covers use value and exchange value and labor value and money value etc .Here we discuss money value. The definition of value, without human face never can establish its own identity. Such definition has also affected the theory of value of money developed by JM Keynes, and Irvin Fisher and diverted to one sided approach rejecting social approach. The measurement of 'value of commodity which is based on labour are significantly varies from that of 'value of money' which is based on 'rate of consumption' and it is different all dimension. Both of these concepts have two extreme meaning.Some classical economists like David Ricardo has more or less succeeded to some extent and incorporated role of labour to overcome the ordeal from marginalist thought of subjective valuation and after it more specifically Karl Marx give labour oriented method used to measure the value of commodity. But Karl Merger Jevons and Marshal - marginal economist - give psychological and subjective factors in the determination of value of commodity.

In this work I attempt to prove neither price level nor volume of commodity available for sale nor does quantity theory of money have a role in the determination of value of money. Instead of it pattern of the distribution of goods among people representing majority can be best way to determine value of money The main function such as 'store value' and 'medium of exchange' functions remains to history and can never performs as long as money became a commodity for which the price is determined by free market. Gold coins - an example of commodity money - has intrinsic value equal to the value it contain and illusion, uncertainty and anticipation cannot change and as such this money never create spurious value, as generated in financial market .The money is financial instrument, either gold coin, or legal paper, notes, with frequency of market value given velocity of circulation and, live in circulation giving stimulations for production and capable to use as settling debt created for appropriating benefit of GDP. The money is financial instrument or exchange media, either coin or motes or both, live in circulation having given or minimum productive velocity of circulation used to settle debt in exchange or in the enjoyment of part of gross produce as well as increase in employment utilizing natural resource.

\section{'Natural Value' (Social Value) of Money}

The term 'value' - to incorporate it to society as a whole — must be understood, in wider sense if we want to eliminate socially, injudicious approach in the analysis of value. The 'value concept' that discusses as a subjective phenomenon in isolation with society and or that discuss without accounting their in come, rate of use of goods and minimum requirement of progressive life is non plebiscite and leads value concept of economics to lethargy science. Such discussion without inclusion of 'social value' aspect will lead to false conclusion resulting to false advice. How can we be calculates the value on individual bases as long as Men being social animal and his interaction will result information of social value? The individual interest which cannot fee from bondage from selfishness is most often come against social interest as Marx quoted. The study of subjective value is equal to negligence to social aspect and acceptance Lucifer for self interest realization The total value to society should never been estimated as summation individual values taken as whole. Such value estimation is based on 'marginalist 'view of subjective and psychicanalysis. It was introduced by Carl Merger and William Stanly Jevons vide their 'subjective value method;' and but has failed to estimate social value by such approach. Because total of individual values is, most often come, against social value andoften contradictory and defame social interest. Money, like commodity has social value and search of this value is prime responsibility of economist study on value. The value of product, as that of Marxian concept, has been determined byaverage labour hours required for the production of that product. Similarly value of money is not subjective and it has social aspect and value is generated from society and it cannot separate from social value imposed up on money 
generatedfrom distribution of money The term 'value 'in economics has been interpreted from physiocratic period onwards and has been defined incur porating 'time element' and 'labour force' and scarcity element as a determinant of value and there was no consensus of opini on. Quesnay and physiocratic writers of 1750 and1760 were observed that value is extracted from agriculture labour. Adam Smith (1723-1790) asserts that labour, all source, either manufacture or service or industrial field, is the real measure of exchangeable value of all commodities .David Ricardo (1772-823) attempted to construct a political economy consistently cent redup on labour theory of value. But, according to Marx, workers sold not labour itself but labour power to create value.

Marshal, never mentions word value and said that and differed mainstream of economics to prove that demand and supply side jointly determines price( value to him). JS Mill(1806-1873) rejected labour theory of value and incorporated all factors brought to production process contribute for formation of value( principles of political economy), Jevons - subjective economist - emphasized 'time element 'The subjective theory of value - denialof intrinsic value - supports the inference that all voluntary trade is mutually beneficial and the state of mind of user determines value than labour. An individual purchases a thing whenhe feel that the goods has values more than the values of money he offers in trade; otherwise he wouldn't make the trade., He would keep on purchasing the thing he values more highly as long as value confers by goods under purchase provide benefit equal to or greater than the value of exchange. Likewise, the seller agrees to trade only if he values the good less than the price he receives. In a free market, both parties therefore enter the exchange in the belief that they will receive more value than they transfer to the other party. The subjective theory contrasts with intrinsic theories of value, The labor theory of value] which holds that the economic value of a thing is contingent upon how much labor was - necessarily - exerted in producing it - under the condition, however, that this "thing" has a use value. For example David Ricardo said, "The value of a commodity, or the quantity of any other commodity for which it will exchange, depends on the relative quantity of labour which is necessary for its production, and not as the greater or less compensation which is paid for that labour."David Ricardo viewed the role of labour and Karl Marx give Labour value theory in scientific line and gives human face in it and found that any attempt to do so will lead economics in to dismal science .Either labour value theory or subjective value theory is reliable and cannot determine the social value of money .Veblen (1899-1953) has deviated such orthodox definition of money and its value and approached in social value aspect (Thorstein Veblen.. Theory of the Leisure Class) There are many essays on quantity theory, velocity of circulation, inflation etc ,but there were no theory regarding the social value of money especially in the contest of basic needs of people. Modern economists like Pathinkin and JM. Keynes has used liquidity approach — which is based on quantity theoryto measure the value of money. Unlike value of commodity as all of them agreed that, the value of money has separate entity and it cannot be determined by price level. The value of money is neither depend on labour spent to produce it nor it does relates to subjective and marginal approach .It has social base and derives from 'velocity of exchange function of money' (rate at which quantity of money in circulation passes through the people representing middle class in a given time and make them to enjoy MRPL — same extent - of people) among majority and whose share received from the net growth of GDP. No precise definition is given to the value of money. Yet there are various interpretations are given regarding factors that deter mine the value of money in a given time and to compare to that of another period. One may feel that the variation in the value of money is the difference or gap created by changes in the purchasing power of money due to rise or fall in the general price level in the definite period.

The price maybe compared as retrospection, with that of another period. It is not quality. It is loss of or gain of purchasing of money in comparison with another period. In our concept, the value of money is decided by 'rate of service of money received by each thousands of people from the given money. To obtain high social value for money, this rate should be sufficient to maintain minimum requirement for progressive life, in a given growth of GDP. The value i.e. social value of money is dependent on availability of MRPL out of given money .The rate of use of GDP possible out of given money is also important in this respect and the rate of use of GDP should rise to maintain MRPL. Let assume that total money in the circulation is Rs 100000 and total population in the country is 1000 - the average money received by each thousands of people is Rs 100 . This does not mean that all people do have 100 each. Some has 150 and others have less than 50. If Rs-100 is needed for maintaining minimum requirement of progressive life, and if $75 \%$ of this members are receiving income equal to or more than Rs 100, then the value of money is high for them. The social value of money is equal to rate of growth of availability of MRPL out of given change in the average incomefor each group of thousand .If $80 \%$ of people can make use of MRPL after change in the price, the Social of money is equal to $80 \%$.Such nation can be called as nation of high money value. If things are reverse in a nation, such nation is needed to call as nation with negative Money Value. If given change inthe price can make them to obtain MRPL at 50\% of people in the rate, instead of $75 \%$ earlier, such change is leads to negative social value of $\mathrm{f}$ money. In another example let us assume that in 2005, preciously 135 members out of 1000 members are able to maintain MRPL at inflation rate of $5 \%$ and, after growth in percapita income and employment, the rate has increased to 155/1000 in 2008 at 
inflation of $6 \%$. This means that rate of use or function of money has categorically raised to 155 instead of 125 earlier in 2008 and this is took place despite there is increase in the inflation rate and value of money rise corresponding to growth in MRPL. The value of money estimated by price level and quantity of money in circulation is ignominious for economist of welfareeconomics. The value of money is not determined by single parameter such as rate of use. But MRPL and growth in the quantity of money can be an important in the determination of social value of money than quantity theory. The social value of money is different from private value and should not compare. The social values of money are dependent MLPL and it never dependent on inflation and rather depend on spurious value generated out of inflation. The rise in the price without growth in GDP and without growth any net addition to value on the product- after innovation - there appears spurious value. If MRPL falls, social value of money falls even in the absence of inflation. If MRPL rise after the innovation of technology on product which results in the arrival of new products, and percapita income remain unchanged the social value of money falls The MRPL is tendency to rise and never show downward flexibility. If MRPL rise without corresponding growth in percapita income, the social value falls The MRPL never falls and it tent to rise in as long as new product came in to being and became inevitable part of life .If MRPL falls, which does not happen in real world, the Social value of Money fall. In real World where innovation in the production change way of life faster, we cannot anticipate the fall in the social value of money and the MRPL has tendency to rise and never show downward trend. The MRPL and subsequent Social value of money is dependent on growth of per capita income among people representing majority .If MRPL rise, without corresponding growth in the per capita income of majority of people, the social value of money falls. The rise in the price level, is accompanied by growth in the per capita income the social value of money cannot fall The correlation between GDP and Rate Use is important in the analysis of Social Value of money. The whole GDP cannot be included in the list of MRPL because it may contain luxurious items and semi luxurious item. Only the item that became part of life, as a part of progressive life, are included in the list of MRPL. The portion of GDP that covers MRPL is core of GDP that determines the Social Value of money. The portion which is not necessary and used as luxury item, but that can be ceased from the consumption without any adverse effect on progressive life is Spurious part of GDP for MRPL is concerned. If GDP rise, the rate of use of MLPL should have to rise correspondingly and it is necessary condition for risingsocial value of goods. But the situation in reverse and the increase in the rate of use is not necessary condition to have corresponding growth of items of MLPL. The accumulation of income in few hands and growing inequalities of income reduce rate of use of money and reduce social value of money. The production and use of GDP are belonged separate component. The tragedy is that GDP arethe result of all section of people but its uses are exclusive right of income class or related t The GDP, as we know, is sum of goods and services, marketed for sale, excluding imported goods and its value is not dependent on the quantity of goods exchanged in the market or total goods produced .It is not the quantity of goods and service produced in the country that determines the social value for money. Though the quantity plays a significant role in the social value product, the rate of use of money among various segment of people, has occupied a dominant part in the determination of social value of money. The volume of GDP and its Rate of Use simultaneously determines the Social value of GDP .If GDP rises and Rate of Use falls, the social value of GDP never rise and vice versa. On other side, if GDP rise by 10\% and Rate of Use determined by MRPL is rose by only $5 \%$, then Social value falls by $5 \%$. But remember that, if GDP falls by $10 \%$ and Rate of Use rose by $15 \%$, then such growth of social value, which is not proportional, does not lead to growth in social value and it rather results in less proportional growth in social value than actual growth in the rate of use. In order to achieve higher social value of GDP, the Rate of use should grow more than growth rate of GDP. The growth in the technology has vital role in the expansion of production. But it is foolish to conceive that advance of technological innovation in the products determines the value. But the process by which gross domestic product is distribute between people in more equally and create demand for goods from all those who is in need, is important role to be decided by the Government of democratic set up. It is indicator that decide social value The money value is neither depends on demand and supply of money nor on level of price or inflation. In other words the money value is depends on 'product population ratio' than quantity of money in circulation which in turn is determines by velocity of circulation of money. The value of money is dependent on number of people per thousand can enjoy this MRPL, which in turn depend on product population ratio. The social value of money is, I think, the most reliable scale for estimation progress of nation The value of money is related to price level and, quantity of goods available for sale in the market, The value of money can't be interpreted with price level and the same changes according to price level The value of money has been interpreted in many ways and some of which relates to price level, and others connects it to subjective estimation of inter personal comparison. The value for money cannot contain in the money andpsychological factor is important. Some argue that such value is dependent on total volume of goods marketed for sale in relation to total money in circulation In economics the value of money is, inseparably relates to rising price or inflation and it is a situation before and after rising prices. The range of value - purchasing power, which is running in between these two extreme periods, is the value of money. If price of $1 \mathrm{~kg}$ wheat rise from Rs 5 to 7 , the buyer can able to purchase less 
than $1 \mathrm{~kg}$ of wheat out of same money of Rs 5 after rise in the price. The value of money, contrary to classical and Keynesians assumption, cannot depend on price level. Such value is depen ding on rate of usage of money. The money never, by itself, determines its value. The goods is produced in search of money and people who wants to purchase the goods out of money can act an significant role in deciding value of money. The ratio of money to people determines usage rate of money Thus the Natural Value of Money (NVM) is related to Rate of Use of money' as well as velocity of circulation of money in given time. It has no relation to intrinsic value or to non intrinsic value. It is depend neither on psychological nor on price income relationship. The social value of commodities such as Diamond or wheat is determined by the commodities which are used by larger number of people. In the same way, the social value of money or NVM is determines by Rate of Use of money. The usage rate is number of people in given thousand of population can make use of money in the circulation to maintain Minimum Requirement of Progressive Life .In this case the wheat the commodity that uses by majority of people and it has high social value than Diamond .. However natural value of money is similar in many respects. It depend on how many people can able to use of the money which put in to circulation as a common property - the everybody has equal right to use the property .It is the natural objective under which money is printed Just as value of commodity, as I have said, is determines by number of people per thousand makes use of such commodity instead labour content in that commodity., Similarly, the value of Money is determines by number of people per thousand can make use of the money to maintain Minimum Requirement of Progressive Life .There is no value for money when it is not used. The greater the number of people can enjoy the use value $f$ such money, the greater is the value to people. The actual ratio of money to commodity determents the value of money The value of anything, for society as a whole, cannot be dependent either on labor or on subjective attitude of the user. Marx finds an solution to it and takes averages of labour hours to determine social value of commodity The average labor spent for the productions determines value of goods. This quality give money separate identity of its own and it has no existence of its own without good and that give blood and life money, in turn, it is capable to determines the value of goods in the market. The value of money is not relates inherent quality of money and it is determined by quantity of the product that can be purchased out of given money and is not subjective quality and it that exhibits irreversible and uncompromising quality of accountability to the society and it is not entitled to provide subjective benefit. For money, social value is important because value of money is subject matter of society. In this sense the outward factor that shapes and determines value is need to be excluded in the real value for society. The macroeconomic vision of value - put forth by JM Keynes and Karl Marx - highlighted the possibility of accumulating artificial value and questioned the role of uncertainty, illusion, anticipation, people's apprehension of worth and finally demand and supply factors, in deciding the value. Such a vision appears and misleads us if value estimates by external factors The social value of money is tells the relation between service of money received by each men per thousand of each group of population to maintain minimum requirement of progressive life and average product available for sale in a given size of population in the market. The social value of money is nothing other than Rate of Use of money. Like the rate of use determines the social value of commodities, in a given time - number of times and number of members per thousand of people uses a given commodities to keep MRPL, the social value of Money is also determined by Rate of Use of money. The rate of use of money falls when it concentrates in few hands and it continues to fall as long as an inequality of money increases. The rate of use of money is the number of times money travels from one hands to another. The velocity of use or velocity of circulation of a given unit of money among lower income class - constitute majority - determines its social value. If money is circulating or using among one or two percent of people, the value of money losses to the extent 99 and $98 \%$ of people (I) The rate of use is dependent of money which, inturn, is depend on Growth of GDP and supply of money correspond to .Thus the value of money is dependent on quantity of goods marketed for a given size of population who demand it to meet progressive requirement of life. Since goods are to increase in according to progressive requirements of every size of population, $10 \%$ growth of population requires more than $10 \%$ growth of GDP and more than $10 \%$ of money supply(2) The value of money is, to great extent, determined by growth of middle class. But unfortunately middle class are vanishes either in to lower income class - very larger percentage - and or in to elite class - minority class. This disappearance reduce percentage of lower income class which, inturn, reduces the rate of use and accelerate diminution of social value, in spite of goods are marketed in large quantities The Rate of use is determined by growth of middle class but eminent economist including, Milton Friedman, fisher and Steve give least importance to Social Value determined MRPL. It is diminishing alarmingly recently after 1960. Such attitude is purely bias. The more growth of middle class, the more will be the Rate of use or consumption of MRPL and, the more will be Social Value of money .The most disappointing event, in USA occurred in the course of middle is the disappearance of middle class in to very low income class. The bulk of America's middle class wealth was tied up in their homes and rate of use of various commodities do not satisfy the requirement of MLPL and social value of money falls. When the real-estate market wiped, all of this net worth is virtually out, and the middle class was essentially decimated. Moreover, the faith in the American economy which is depend on growth of middle class, has been shattered and rate of use of MRPL falls 
desperately and even Fitch (a bond rating agency) is talking about downgrading our debt. The middle class really is the social glue and holds society together. Then America is in the process of becoming unglued. A middle-class household is frequently defined as one with an income between 75 percent and 125 percent of the median household income. If so, then the middle class - which falls into an income range of $\$ 15,100$ to $\$ 25,200$ in 1982 - has declined from 28.2 percent of the population in 1967 to 23.7 percent now. Even when slightly different definitions of income factors constituting a middle class are applied to the statistics, the trend is not reversed. The American middle class is disappearing.. The rate of use is depend on velocity of circulation of money among middle class This velocity is low among elite class and money is goes in to bank, as dead money In the definition itself I have mentioned that any instrument with given velocity are eligible to be called as money. If money is exchanged only among one or two customers and exchanged is carried out giving stimulant or incidental effect on producers and exchanged is blocked there, then such money can never be called as money. All money, without given velocity of circulation are not eligible to be called as money. As long as rate of use is depend on velocity of transaction, the social value of money falls according to diminution in the circulation The middle class is disappearing, and hence it is foolish to believe that the social value of money can be enhanced mere by forcing Rate of use among high income class only. If rate of use is increased among high income class representing only $15 \%-20 \%$, it do not pushup social value of money because middle income class representing larger proportion of population are out of the market and became pauper The value of money never relates to inflation or deflation as believed by thinkers but social value of money do not associate with inflation or deflation rather depend on rate of use. The mild inflation may be there or mild deflation may be there but the social value of money is depend on MRPL obtained at deferent level of employment The deflation is the result of diminish in the rate of use of money. The contraction of MRPL leads to diminish in the rate of use It is true that inflation results rise in the price and reduce MRPL making big and big gap between required money for MRPL and actual money received for maintaining MRPL But the growth of employment generate money to be active and enhance commodities to come under MRPL and nullified the effects of inflation

\section{Conclusion}

The commodities with highest rate of use - pure air we breathe and pure water we drink - have high social value than all other commodities. This goods are subject to the invariable fact of diminishing value in market economy which is controlled by thrive for accumulation of profit .The disappearance of original value of such items can be generated in one place and penetrates in to another place through conductivity quality of air and caused to affect in all other nation until diminish in the value such commodities equalized thought out the world. The pure water and pure air are social property of world used all inhabitant in this planet and it has social and universal value of $100 \%$ in the sense of its rate of use .Unfortunately this precious commodities became more and more polluted by thrive for profit and as such there value is diminishing at every day. 